\title{
The Teaching Application of TESOL Model in English Grammar "Past Continuous Tense"
}

\author{
Rui juan-Lin \\ School of English Language and Literature of Xi' 'an Fanyi University,Xi'an, Shaanxi 710105, China \\ Corresponding author.Email: 354276603@qq.com
}

\begin{abstract}
With the development of education globalization, the demand for international English teachers with standardized professional teaching skills is more and more urgent. In view of this situation, TESOL curriculum design emphasizes that the focus of language teaching is to use meaningful language in a wide range of contexts, which covers the advantages of the current English teaching methods and makes improvements. TESOL teaching is a teaching method with "students as the subject and teachers as the auxiliary", and the ESA teaching model has been applied to English grammar "The Past Continuous Tense" and achieved good results. TESOL courses in English-speaking countries are impartial, quantifiable, forward-looking and exemplary, which can provide certain reference and inspiration for foreign language teaching in China.
\end{abstract}

Keywords: TESOL, ESA teaching model, English grammar, the past continuous tense

\section{INTRODUCTION}

TESOL is fully known as "Teaching English to Speakers of Other Languages", Chinese translation as "Teaching English to non-English Speakers", which refers to English Teaching for students whose second language is English. According to their mother tongue,the target audience of English teaching can be divided into two groups: native English speakers (such as British, Canadians, and Americans) and non-native English speakers (such as Chinese, French, and South Americans). The teaching object of TESOL belongs to the second group. As it is "external", TESOL teaching methods pay more attention to learners' native language and cultural background. .

TESOL teaching philosophy originated from the United States, under the student-centered teaching philosophy which has its specific teaching mode. The first factor is the curriculum design. The teaching material in the TESOL teaching is not fixed, and the teacher prepares in advance appropriate articles or material issue settings according to the lecture topics. Secondly, TESOL teaching concept attaches importance to teachers' classroom organization ability. In the TESOL class, and the teacher will use a quarter of the class time to teach the content of this lesson and the learning skills to be mastered. After the explanation is completed, students will have a group discussion. At last, students will be asked to demonstrate the knowledge of this lesson on the stage. In this process, students can always focus on classroom teaching, so that every student actively participate in classroom learning. At the same time, the teacher also integrated into the discussion group, solved problems for students in time, answered questions and pointed out the areas that students needed to improve. TESOL teaching enables teachers to observe the classroom performance of each student and make corresponding learning strategies and after-class guidance according to specific conditions.This teaching method embodies student-centered teaching philosophy, teacher-student interaction and cooperative learning between students in the foreign language. As the subject of learning, students have changed their role from the passive receiver of external stimulus and the object of knowledge indoctrination to the subject of information processing and the active constructor of knowledge meaning[1]. It is well known that the goal of education is to cultivate people, which is related to the basic issue on the social role and quality. It is the starting point of educational practice[2].

\section{THE CONTENT AND CHARACTERISTICS OF ENGLISH TEACHING METHODOLOGY}

\subsection{Grammar-Translation teaching methodology}

The grammar-translation approach, perhaps the backbone of language teaching for hundreds of years, is still used in today's classrooms. The basic principle of the methodology, as the name suggests, is to acquire a language by looking for the equivalent in the student's native language and the language being learned. In fact, it is a representation of a system of translation. The main disadvantage of grammatical translation method is that it is not conducive for students to truly acquire the natural input of language. Students learn the rules of language rather than the actual application of the language 
itself.This method also requires teachers to be proficient in the students' mother tongue.

\subsection{Audio-Lingualism Teaching Methodology}

The listening and speaking methodology is based on behaviorist's theoretical language teaching method. According to this theory, a lot of learning is the result of forming habits through conditioning. Therefore, to a large extent, the listening and speaking teaching method adopts the teaching mode of intensive repeated practice for a long time, in which students will get accustomed to the correct use of language. In fact, the listening and speaking approach is to some extent obsolete, because most linguists believe that language learning consists not only of forming habits, but that speakers of a language are able to process language more effectively from the knowledge they acquire. However, although this teaching method is very limited in its application, it is still effective for students at a lower level.[3]

\subsection{Presentation, Practise and Production}

In this teaching method, the teacher first needs to present the context and situation of the language, and explain and show the meaning and form of the new language. Secondly, students practice making sentences (including drills) as required, and finally enter the output stage of using the language more creatively.

The teaching methodology of presentation, practise and production is also called as PPP method in short which is proved to be very effective in simple language teaching at a lower level. For high-level students who have mastered skillfully and do not need to show obvious language output, this method is less effective. In fact, many teachers or language training centers still use PPP teaching methodology, because it lacks much flexibility and courses tend to be "teacher-centered". Instead of focusing on the language itself, the students were asked to complete a task (using an English context).When they have completed the task, if necessary, the teacher can provide some language skills to help them solve some of the problems encountered in completing the task.

\subsection{Communicative Language Teaching Methodology}

Communicative approach emphasizes the importance of language functions (such as consent, invitation, suggestion, etc.) rather than relying solely on grammar and vocabulary. The activity of Communicative Language Teaching (CLT) usually requires students to use the Language in real life, so role-play and simulation have become a common mode for the method. Compared to the accuracy of Language, CLT emphasizes the completion of task. For example, students usually sit around in a circle and decide what topics to talk about, with the instructor (standing outside the circle) helping to discuss language problems if necessary.This approach is designed to help teachers focus on "student-centered" classroom models and allow students to choose topics and languages.

\section{ESA TEACHING METHOD IN TESOL TEACHING MODE (ENGAGE, STUDY, ACTIVATE)}

Admittedly, with so many different teaching methods, there is no clear answer as to which is the best, since the teaching effect depends on the individual situation, educational level and specific needs of teachers and students.Actually, each method has its advantages and disadvantages, but the general teaching conclusion is as follows: (1)Students need to be exposed to the language as much as possible. (2) Students need a certain amount of teaching input.(3) Communicative tasks can provide real learning scenarios, but students' learning ability may not be enough.(4) Effective language learning needs to reduce anxiety and stress. As far as possible, teachers encourage students to "discover" the application of language. English is not only a tool of communication, but also a tool of thinking. At the same time, learning and using language can further promote the development of thinking.Learning and using languages other than your mother tongue can enrich your way of thinking and further promote the development of your thinking ability.Many activities in English classroom teaching can promote the development of learners' thinking ability[4]. So, when students need to be motivated to acquire a language, they need to be exposed to it frequently. A new approach has been activated by Jeremy Harmer, an internationally renowned English teacher education expert, who names these elements as "ESA" (Engage, Study, Activate), which is the "introduction", "learning", and "activation". This approach allows the application of all the previously mentioned conditions and gives the teacher a lot of flexibility in the classroom. ESA is particularly suitable for training freshmen and new teachers.

The Engage phase is the first part of the course.Teachers will use various activities and materials that attract students, including games, music, interesting pictures,stories, etc., to stimulate students' interest and engage them in the course, which helps to create a good and relaxing language learning environment. The skills required in Engage can test the learner's ability to respond to a second language. In other words, at the Engage stage, teachers can obtain the known and needed information of students in class, including the process of language understanding and discovery by learners. Engage not only increases the opportunity and time for students to speak, but also reduces the amount of teachers' explanation, which reflects the purpose of "student-centered" in Tesol teaching, which is an important part of ESA method, and this stage is also the 


\begin{abstract}
"warm-up" stage for students' learning. In essence, Engage aims to get students to think and speak as much as possible in English before moving on to the next step.

Second, in the Study phase, students will focus on acquiring language (or information) and how it is constructed.This step begins with the practice of pronouncing individual words and mastering verb tenses, followed by an introduction to language points and training to ensure correct pronunciation. When students master the language points, the teacher will issue exercise books to check their understanding and consolidate the knowledge points. At the same time, the teacher will review their answers to the questions and check for gaps. Finally, students can study a text or study a text in groups to learn about the author's writing style. Whatever the method, learning means that the student focuses on the construction of the language.

Finally, in the Activate phase, teachers should encourage students to use the second language they know to communicate as frequently and "freely" as possible. During this period, teachers should focus more on fluency than accuracy. Typical activation activities include role-playing, debating (for higher-ability classes) and story retelling. I give the following teaching case, applying ESA teaching strategy to the explanation of English tense of "past continuous tense".
\end{abstract}

\section{THE TEACHING APPLICATION OF "THE PAST CONTINUOUS TENSE" UNDER ESA}

\subsection{The Engage stage}

A very interesting introduction is that teachers can assume a detective story, such as "Jackson died at 8:00 p.m. yesterday" and then throw a question to the student, "If you were a policeman, what question would you ask? What were you doing at 8:00 PM yesterday? What were you doing when Jackson died?" This is an interesting opening, and students are bound to think about their own absence from the scene of the crime, so it makes perfect sense to use the past continuous tense.

Student A: I was having a bath at 6:00 yesterday. I was having a bath when Micheal Jackson died.

Student B: I was watching TV at 6:00 yesterday. I was watching TV when Micheal Jackson died.

\subsection{The Study stage}

According to the requirements of ESA, students need to master the construction of "past continuous tense" and relevant language points. Past Continuous Tense=Past Tense of the auxiliary verb be(was/were)+the Present Participle (verb+'ing')

Affirmative: a subject+was/were+verb+ing Negative: subject+was/were+not+verb+ing Question: was/were+subject+verb+ing
Students can practice the materials given in groups. Teachers can check for gaps and check their language points to prepare for the third stage: Activate.

\subsection{The Activate stage}

The teacher can present a scene that allows students to freely exert their imagination, such as: "An Diamond was stolen at 9p.m.yesterday, so everyone was to be investigated. One student played the role of policeman and asked others what they were doing at 9p.m.yesterday". In this part, teachers should encourage students to communicate as "freely" as possible. Teachers should pay more attention to the fluency of language rather than accuracy, and encourage all students to retell the story according to the scene without fear of making mistakes.The above is all the steps of applying ESA teaching strategy to the explanation of English tense of "past continuous tense", which can be improved improve the teaching efficiency.

\section{CONCLUSION}

TESOL, like the "Teaching Chinese as a Foreign language" in China, is of great significance to engage in the teaching of English as a second foreign language worldwide. TESOL model is applied to English teaching, which shows different task-based teaching activities according to different categories, so as to improve students' English learning ability. According to TESOL teaching concept, a quantifiable and demonstrative English teaching syllabus is formulated. In this way, it can give better service to teachers, and make English learners get direct experience and put what they have learned into practice.[5]

\section{REFERENCES}

[1] Gao Xin (2014) Constructivism based Interactive College English Vocabulary. J. Journal of Hubei University of Economics, 6: 205-206.

[2] Gu Mingyuan (1991) Dictionary of Education. Shanghai Education Press, Shanghai.

[3] Levelt,Willem(1989) Speaking:From intention to articulation, The MIT Press, Cambridge.

[4] Waters, A. (2006) Thinking and Language Learning. J ELT Journal, 4: 319-328.

[5]Liu Sen (2018) English Teaching based on Discipline Core Literacy-Reflections brought by TESOL China Congress in 2018. J. Research on Teachers' Education, 9: 56-60. 